\title{
An Analysis of the Comprehensible Input of TPRS
}

\author{
Li Qin \\ School of Foreign Languages \\ Jilin Institute of Chemical Technology \\ Jilin, China 132022
}

\begin{abstract}
TPR Storytelling (Teaching Proficiency through Reading and Storytelling or TPRS) is a method of teaching foreign languages. It applied in many world language classrooms in the America as well as many other countries. Comprehensible input is an important element in TPRS, it is also a key to achieve the goal of teaching in TPRS. During my stay in Barrie School, MD, USA, in which TPRS is taken as a main teaching method in the world language department, I experienced and learned this teaching method and understood the comprehensible input( shortened as CI) of TPRS. The thesis analyzes the comprehensible input in TPRS. In this article, the topic is discussed in several aspects which includes the introduction of TPRS and comprehensible input, how do TPRS teachers do CI, how to deal with different tense in CI, the connection between $C I$ and personalized questions and answers (PQA), the connection between $C I$ and output, the connection between $C I$ and writing, the connection between $C I$ and circling and how could teacher do comprehension checks in TPRS classrooms.
\end{abstract}

Keywords-TPRS; comprehensible; input; output

\section{INTRODUCTION}

TPR Storytelling (Teaching Proficiency through Reading and Storytelling or TPRS) is a method of teaching foreign languages. The teachers use TPRS by reading and storytelling to help students learn a foreign language. TPRS was developed by Blaine Ray during the 1990s, as an experienced Spanish teacher, he himself took TPR approach as his teaching method and found both advantages and limitations in this specific teaching approach. In his teaching and researching, he accepted the idea of Comprehensive input (CI) in The Nature Approach by Krashen and Tracy Terrell. He tried to use TPR trough storytelling which gradually developed into the method which Blaine named as TPR Storytelling. Usually, it takes three steps to develop a TPRS lesson: establishing meaning, asking a story and reading practice. TPRS is carried on by three main steps. Step one, the new words or phrases are regarded as the structure in TPRS, the new structures are showed on the board with their comprehensive meaning. The teacher give lectures by using a combination of translation, gestures, signs and personalized questions and answers ( PQA) ; in step two, the teacher creates a story by new structures, what the teacher does is to keep asking for key information, the students provide clues and ideas and help to find the characters and plots which attracts the attention most. In step three, these same structures are used in reading.
Comprehensible input is language input that can be understood by listeners despite them not understanding all the words and structures in it. It is described as one level above that of the learners if it can only just be understood. According to Krashen's theory of language acquisition, giving learners this kind of input helps them acquire language naturally, rather than learn it consciously. (http://www.teachingenglish.org.uk/knowledgedatabase/comprehensible-input)

\section{THE WAY TPRS TEACHERS DO CI}

To do Comprehensible input, a lot of techniques are involved which include signing, gesture, circling, recycling, reaction, comprehension checks, asking story, develop story, use fun skills, PQA(personalized questions and answers) to develop the story. Teacher controls the story but the teacher develops the story by keeping asking details from the students. It's also a trick to keep the attention of the students. Students are excited to add details to the original story and have a feeling that the story is their own. But actually, the teacher has a fully command of the development of the whole story. By letting the students provide different details, the teacher is seeking the most funny and special elements that would keep the students focus during the process of communication with the learners. The teacher keeps denying the suggestion until the one expected or one wonderful idea showed up.

Ben Slavic mentioned in TPRS in a Year,"...remember that all you have to do be successful at TPRS is to simply circle and personalize each sentence, going slowly...". This implied the basic TPRS comprehensible input spirit, that is, make the teaching material understandable, easier to get.

Blaine Ray mentioned in his book:'Language acquisition is not a conscious process. It is something that happens to a person. It happens when one understands messages. ...learning to speak a language comes from hearing it." [Page7, fluency through TPR storytelling] Base on such idea, the basic techniques in a TPRS classroom includes conscientious limitation of the input, clarified language information, first language aid, necessary first language explanation in grammar, suitable speed[ p14[2]]. In TPRS classroom, the final goal is to provide enough comprehensible input, so it doesn't matter how long the story last, it could be a very short story, it also could be a long story last for several periods or even longer. It depends on whether it could attract the students' interests and the 
material or elements in it are valuable for comprehensible input.

\section{ThE WAY TO DEAL WITH DIFFERENT TENSE IN CI}

Blaine hold the idea of "by providing considerable input of both tense in appropriate contexts from the earliest stages of acquisition, students are generally far more able to keep the present and the past separate and to use each much more correctly. [Page53, fluency through TPR storytelling] He believed the idea that all language are not learned but acquired. So language teacher should provide enough comprehensible input instead of just teaching grammar. $[\mathrm{p} 189,[1]]$ Since different tense is traditionally regarded as a part of grammar, teachers used to teach tense. Start with present tense, and then step further to past tense. Students will experience a period of confusion during transition from the present tense to the past tense. TPRS theories tried to avoid this happening. Especially in a story, there would be a lot of past tense. Blaine believed just given a large quantity of language input, different sense just exist in sentences, students gained the tense and sentence naturally without even notice they are learning. So the whole process is acquiring instead of learning.

\section{The ConNeCtion Between CI AND PQA}

Personalized questions and answers (PQA) are a conversation between teachers and individuals in the class about something regarding those individuals. Before you start a story, you list two or three phrases on the board with translations into English (students' first language). [p74, [1]]PQA is an important element in TPRS, as it can attract the attention of the students when the questions are about their individual life or experience. PQA also found a better understanding of the later comprehensible input. Personalized questions and answers helps to personalize the story which would keep the students' interests high. The teachers gets details from personalized questions and use the answers to add details to the story. Students are much eager to learn more of themselves. It makes the story much more interesting if they feel it is their own story instead of others.

There're different levels of questions. It is important to be aware of the levels of questions that your students can handle.[p61, [2]] the teacher would ask different level questions start from yes/no and either/or questions. The second level would be easy questions which can be answer by word or simple phrase. Then the teacher could continue with questions that should be answer by simple sentence. In the next level, the teacher would ask open-ended questions to which students answer original things. In the process of PQA, the story develops and a lot of repetitions are circling, the students get comprehensible input. PQA is important in TPRS classroom as it could provide a large quantity of repetition and attract the students' attention. Students are involved by PQA, acquiring the questions and idea from the teacher as the same structure keeps coming into their ears and minds naturally through the personalized questions. The students do think over these questions when the teacher expects the answer from them and it's interesting to learn the plots of the story by adding details by themselves.

\section{THE CONNECTION BETWEen CI AND OUTPUT}

TPRS teachers share the idea that enough comprehensible input is important. And this goes through a way that the teacher keeps input the target language in different ways, different sentences and different questions. A target word may be mentioned a large quantity of times (counted up to hundreds times for one single target word in half an hour) which just impressed the students a lot. When it's time for students to express, they just speak it naturally, without noticing that how they gained the word. And they also know different questions which also gained from the teachers tons of questions. So the output just happened gradually and naturally after the students acquire the language by comprehensible input.

If the whole process of TPRS comprehensible input and output are examined again, we can find it follows the natural rule of the language acquisition. A baby just acquires the first language naturally by listening for a long period. No one tells a baby grammar or offers explanation, it just a process of input and output, which happens naturally and unintentionally. The connection between TPRS comprehensible input and output is similar. The teacher provides enough comprehensible input, provides the easiest access to the students, and expecting the students acquire the second language. The output of the teaching effect would happen naturally.

\section{THE CONNECTION BETWEEN CI AND WRITING}

In TPRS theories, you wouldn't see writing practice a lot. Part of the reason is that TPRS is a language teaching method. It emphasizes on communication and speech input and output. Another thing should be noticed is that Blaine is a Spanish teacher, most educators in TPRS research is French or Spanish (these two languages are popular in America world language class) teachers. As letters in these languages are similar with English, writing won't be a big problem for American students. Blaine suggests writing assignments are first done orally in class. These kinds of written assignments could include free writing, relaxed writing (these two are regarded as timed writings) and writing stories. Blaine voted for the idea that although spelling is important, the target language writing shouldn't take class time since it would take a long time in which the students could learn knowledge by doing other class activities. As for other languages, like Chinese (learning as a secondary language to American students whose first language are English), TPRS teachers use Pinyin (phonetic alphabets) instead of Chinese character. They believed writing ability could be improved in later study after the students get a large quantity of comprehensive input. The students learn the oral language as the first priority. Some Chinese teacher puzzled on this point. I learned a lot of questions on this at the TPRS workshop in College Park presented by Terry Waltz. As an American who can speak very excellent Chinese and being a Chinese teacher, TPRS teacher and presenter, She showed videos and students works to show that by using TPRS in Chinese teaching, the students can still developed the ability of Chinese character writing 
although most of the time they just get oral comprehensible input.

\section{THE CONNECTION BETWEEN CI AND CIRCLING}

Circling is a basic technique or skill of TPRS. Circling is a way to make a statement repetitive by asking repetitive questions. Circling involves just one statement. [p6, [2]] Circling is very important in TPRS as a main approach of comprehensible input. The teacher starts circling with a statement. After the students get the idea, the teacher will ask a simple yes or no question. The following up question would be an either/or question. Until then, the teacher has repeated the statement in five sentences, but there're still more. The teacher would restate the sentence with a negative meaning. The next step should be the "W" questions. By asking "who, where, when, what..." and get simple answer from the students. The teacher could repeat the positive statement to complete the circle. The whole circling process is a comprehensible input teaching experience, the teacher keep state, restate the sentence and keep asking questions to the students. A lot of repetition is done by this way and it's just effective comprehensible input. A trick the teacher should use is to ask questions in an unpredictable order. It's not easy to distract from the sentence as the students have no idea of when the teacher would ask or whom would be asked especially on some topic they regarded as their "own story". TPRS teachers usually circles different parts of the sentences as well as circling the subject, verbs and objects. Under certain circumstances, the teacher could create a parallel sentence about a student, it makes easier for the teacher to do more repetition and circling, thus, providing enough comprehensible input.

\section{METHODS FOR TEACHER TO DO COMPREHENSION CHECKS IN TPRS CLASSROOMS}

Many experienced teachers in TPRS report that the best way assess comprehension is simply to ask the class to put up hands with ten fingers indicating $100 \%$ comprehension, five fingers indicating $50 \%$ comprehension, etc. It is recommended to do this skill once every ten minutes or so during CI. ... Another faster way to do a comprehension check is to simply ask the students to give thumbs up, sideways, or down as an indication of the level of comfort with the speed of the input you are providing. [Ben Slavic, TPRS in a Year! 4th edition.] TPRS can also be checked by unannounced tests, Blaine regarded that short term memory is not the goal of TPRS teaching but long term memory. A method for TPRS testing is to check the barometer student, notice how well they do after comprehensible input, what their understanding of the grammatical and vocabulary items. The check could be oral, just listen to them when they speak, the teacher could also read the stories they write and check their timed writing. Since oral output is very important in a TPRS classroom, most TPRS teachings put oral output on a very important position.

\section{CONCLUSION}

Comprehensible input is an important element in achieving the goal of teaching in TPRS. The comprehensible input in TPRS could be analyzed in several aspects which includes the introduction of TPRS and comprehensible input, how do TPRS teachers do CI, how to deal with different tense in $\mathrm{CI}$, the connection between $\mathrm{CI}$ and personalized questions and answers (PQA), the connection between CI and output, the connection between $\mathrm{CI}$ and writing, the connection between CI and circling and how could teacher do comprehension checks in TPRS classrooms. Techniques need to be involved to develop the story during TPRS teaching procedure. The basic TPRS comprehensible input spirit is to make the teaching material understandable. There would be a lot of past tense in a TPRS story. By being given a large quantity of language input, different tenses were showed in sentences, students gained the tense and sentence naturally without even noticed they were learning. So the whole process is acquiring instead of learning. TPRS teachers share the idea that enough comprehensible input is important. So the teachers express the target language in different methods and mentioned a large quantity of times. Students gain the target words and expressions naturally, without noticing how they gained the language. The output just happened gradually and naturally after the students acquire the language by comprehensible input. TPRS theory emphasizes on communication as well as speech input and output. Teacher would do a lot of repetition and circling in order to provide enough comprehensible input.

\section{REFERENCES}

[1] Blaine Ray\&. Contee Seely. Fluency trough TPR storytelling[M].sixth edition. 8411 Nairn Road, Eagle Mountain, UT 84005: Blaine Ray Workshops, 2008. 3-238

[2] Blaine Ray\&. Contee Seely. Fluency trough TPR storytelling[M].sixth edition. 8411 Nairn Road, Eagle Mountain, UT 84005: Blaine Ray Workshops, 2012. 5-180

[3] Joe Neilson and Blaine Ray. Mini-stories for look, I can Talk! Student book [M]. Eagle Mountain, UT: Blaine Ray Workshop Inc, June 2005. 2-70

[4] Blaine Ray. Mini-stories for look, I can Talk! Teacher's Guide [M]. Eagle Mountain, UT: Blaine Ray Workshop, Inc, July 2006. 5-120

[5] Jack C. Richards. Reflective teaching in second language classrooms. [M]. London: Cambridge University Press, 1996. 10-98

[6] http://www.teachingenglish.org.uk/knowledgedatabase/comprehensible-input 